\title{
Artrite Rádio Cárpica por Candida krusei: relato de caso
}

\section{Radiocarpal joint arthritis caused by Candida krusei: case report}

Ubiratan Brum Castro ${ }^{1}$ (orcid.org/0000-0002-9304-455X), Auro Sérgio Perdigão de Brito²(orcid.org/0000-0003-15990986), Paula Lemos Carneiro Trindade ${ }^{3}$

1. Docente do curso de Medicina pela Universidade Federal de Minas Gerais (UFMG), Belo Horizonte, MG, Brasil. 2. Residente de Cirurgia da Mão pelo Hospital São Francisco, Belo Horizonte, MG, Brasil. 3. Graduação em Medicina pela Faculdade Ciências Médicas de Minas Gerais(CMMG), Belo Horizonte, MG, Brasil.

\section{Resumo}

Introdução: Artrites sépticas de Cândida sp são incomuns, graves, e podem atingir elevado grau de morbimortalidade se não tratadas adequadamente. Ocorrem por disseminação hematogênica, especialmente em imunocomprometidos submetidos a procedimentos cirúrgicos ou por inoculação direta em pacientes leucopênicos, portadores de câncer, sepse ou doenças autoimunes. Relato de caso: 0 caso relatado trata de paciente imunossuprimido, portador de artrite psoriásica, com artrite séptica devido à Candida krusei - evento raro. Conclusão: Houve boa evolução com antifúngico endovenoso e desbridamento cirúrgico.

Palavras-chave: Artrite Séptica. Candida. Punho. Artrite psoriásica.

\section{Abstract}

Introduction: Radio carpal joint arthritis by Candida sp are rare, severe and may assume high levels of morbidity and mortality if unduly treated. They are caused by hematogenous dissemination, especially in immunocompromised patients undergoing surgical procedures or by direct inoculation in leucopenic patients, as people diagnosed with cancer, sepsis or autoimmune diseases. Case report: The following case is about an immune suppressed patient with psoriatic arthritis who developed septic arthritis due to Candida krusei-a rare event. Conclusion: There was good evolution with intravenous antifungal and surgical debridement.

Keywords: Septic arthritis. Candida. Wrist. Psoriatic arthritis.

\section{INTRODUÇÃO}

Artrites sépticas por Candida são raras. Ocorrem por disseminação hematogênica, principalmente em imunocomprometidos submetidos a injeções intra-articulares e procedimentos cirúrgicos; ou por inoculação direta, verificada em pacientes com leucopenia, câncer, sepse, doenças autoimunes ou uso prévio de antibióticos. Ao diagnóstico, as principais espécies envolvidas são Candida albicans e Candida tropicalis ${ }^{1,2,3,4}$. Relata-se uma rara ocorrência de artrite séptica devido à Candida krusei em paciente com Artrite Psoriásica.

\section{RELATO DO CASO}

Trata-se de paciente F.F.O, sexo masculino, 41anos, pardo, em tratamento de artrite psoriásica, com sintomatologia exacerbada de sinovite em punho direito, com dor e grande destruição articular ao exame radiográfico. Encaminhado ao Serviço de Cirurgia da Mão que propôs artrodese do punho.

Em abril/2015, durante o procedimento cirúrgico, foi visualizada, após a incisão da cápsula articular, drenagem volumosa de secreção purulenta, grumosa, amarelada e de odor não fétido (Figura1). Após realizar desbridamento articular vigoroso, lavagem articular com soro fisiológico, coleta de material para cultura, foi feita estabilização radio cárpica com fios de Kirschner

Figura1. Sinovectomia do punho direito com presença de secreção purulenta.

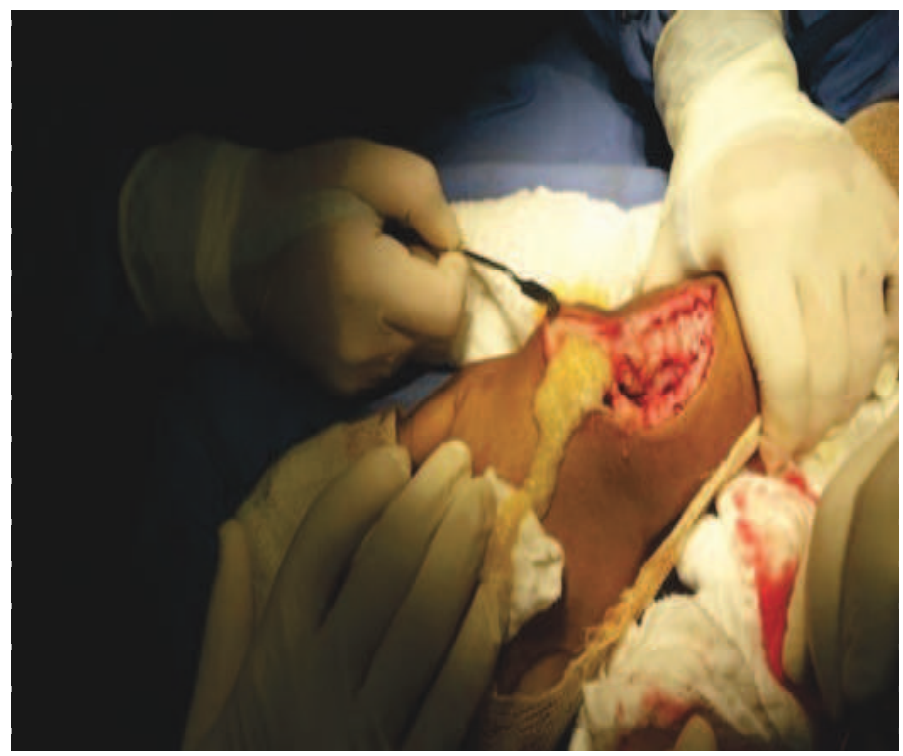

Correspondência: Ubiratan Brum Castro. Faculdade de Medicina da UFMG - Av. Alfredo Balena 190, Belo Horizonte, MG. E-mail: ubrum@terra.com.br Conflito de interesse: Não há conflito de interesse por parte de qualquer um dos autores.

Recebido em: 29 Ago 2017; Revisado em: 26 Dez 2017; 13 Fev 2018; Aceito em: 17 Fev 2018 
Em acompanhamento ambulatorial, na primeira semana de pós-operatório, o paciente relatou leve remissão do edema, que voltou a intensificar-se na terceira semana, sendo acompanhado de drenagem de secreção purulenta, mas sem repercussões sistêmicas. A respeito da análise do material coletado intra-operatório, os resultados de teste rápido para Mycobacterium tuberculosis, pesquisa de BAAR, microscopia ótica direta, culturas bacteriana, microbacteriana e fúngica foram negativas, exceto pela presença do fungo Candida krusei em uma das amostras.

Houve reagudização da infecção após dois meses e perda da fixação com fios Kirschner, sendo necessário novo procedimento cirúrgico - desbridamento articular e retirada dos fios de Kirschner (Figura2).

Figura 2. Radiografia do punho direito depois de retirada de Fios Kirschner

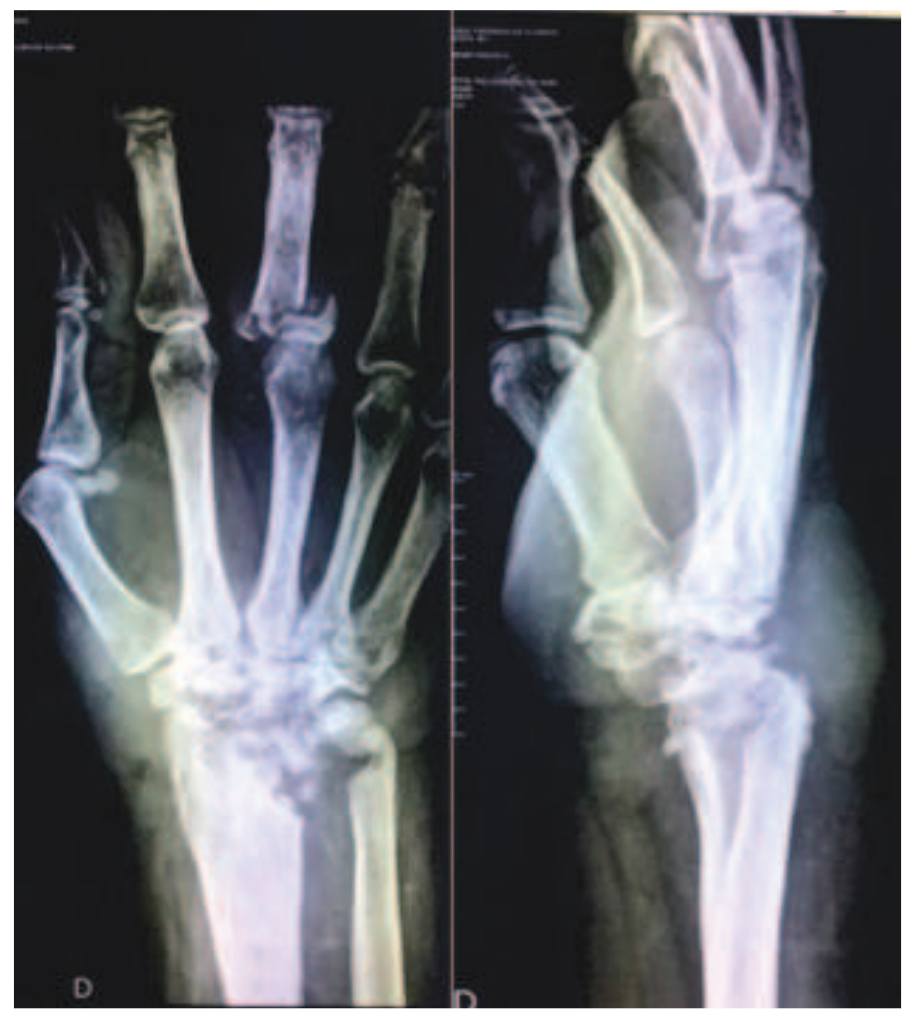

Após essa última intervenção, o paciente intercorreu com pneumonia e insuficiência cardíaca e necessitou ser internado em outro serviço, por questões sociais, sem continuidade ao tratamento do punho.

Retornou ao ambulatório de Cirurgia da Mão quatro meses após essa segunda intervenção (figura 3), e foi realizada nova biópsia articular que reconfirmou a infecção fúngica- todos os resultados de cultura foram negativos, exceto por uma amostra novamente apresentando Candida krusei. Diante do diagnóstico e da ausência correta do tratamento da artrite fúngica, foi estabelecido o tratamento venoso com Anidulafungina por seis meses com a remissão do quadro infeccioso.
Figura 3. Aspecto atual do punho direito
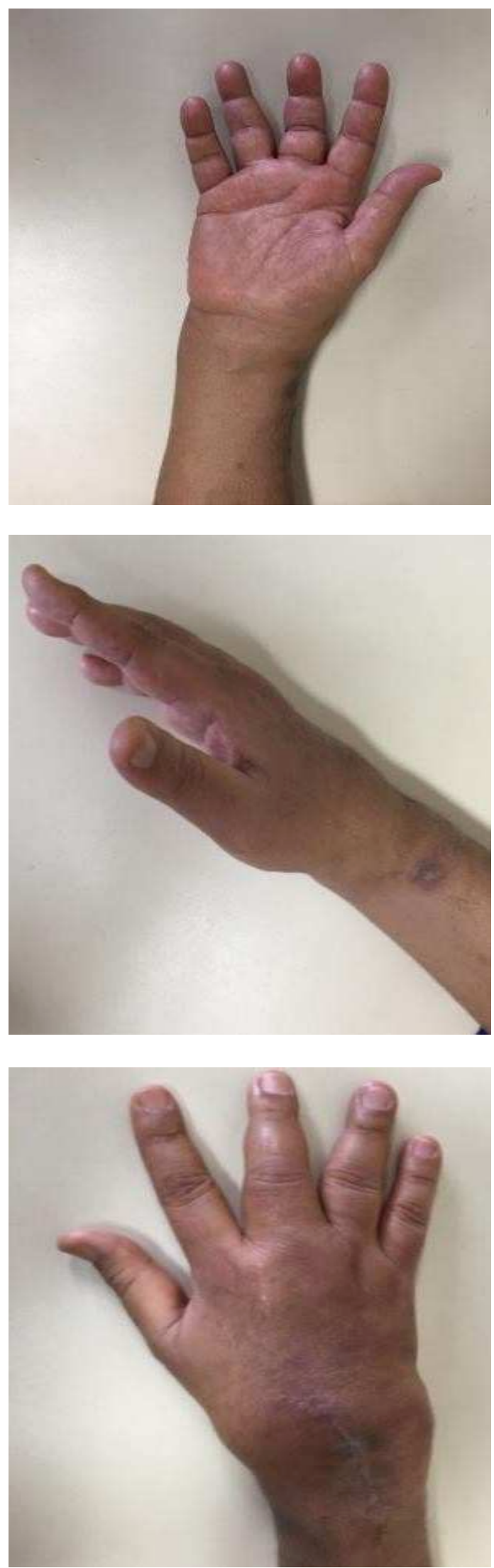


\section{DISCUSSÃO}

A prevalência de candidíases invasivas tem aumentado consideravelmente, principalmente devido ao crescimento da população de indivíduos imunossuprimidos, ao grande número de cirurgias invasivas, ao uso indiscriminado de antibioticoterapia de largo espectro e ao uso prolongado de cateteres centrais ${ }^{1,5}$.

A Artrite Séptica por Cândida sp é um tipo incomum de candidíase invasiva ainda muito carente em determinação de fatores de risco, diagnóstico e tratamento ${ }^{1,3,7}$. Porém, sabese que representa uma infecção que demanda intervenção emergencial com terapêutica efetiva e está associada com significativo grau de morbimortalidade se não diagnosticada precocemente ${ }^{2,3}$.

A maioria dos pacientes com artrite fúngica apresenta dor local, edema e eritema, porém poucos apresentam febre ${ }^{3}$. Os sintomas são insidiosos e podem durar de semanas até meses. Em alguns pacientes observam-se a limitação de movimento da articulação e a secreção purulenta.
A suspeita diagnóstica baseia-se, além dos dados clínicos, nas radiografias simples da articulação, que irão evidenciar a destruição óssea, o acometimento de tecidos moles e até a presença de abscesso em alguns casos. A confirmação se faz através do exame anatomopatológico e resultado de culturas. Ressalta-se que a aspiração do liquido sinovial com identificação do patógeno é o padrão-ouro para diagnóstico de artrite séptica ${ }^{8}$.

O tratamento mais usual envolve abordagem cirúrgica precoce, com exploração e lavagem articular exaustiva com soro fisiológico, e uso de antifúngicos por seis a doze meses ${ }^{3,4}$.

\section{CONCLUSÃO}

O caso apresentado trata-se de um paciente imunossuprimido, em longo período de tratamento de artrite psoriásica, com artrite séptica radio cárpica por Candida krusei. Pela raridade do agente causador e pela falta de dados em literatura, o tratamento torna-se desafiador. De acordo com o relato, pode-se perceber a boa evolução do paciente após o uso de antifúngico endovenoso, associado ao desbridamento cirúrgico.

\section{REFERÊNCIAS}

1. Shaikh Z, Shaikh S, Pujol F, Trauber D, Sam M. Candida tropicalis osteomyelitis: case report and review of literature. Am J Med. 2005 Jul;118(7):795-8. doi 10.1016/j.amjmed.2004.11.027. PubMed PMID: 15989918.

2. Neofytos D, Huprikar S, Reboli A, Schuster M, Azie N, Franks B, et al. Treatment and outcomes of candida osteomyelitis:review of 53 cases from the PATH alliance registry. Eur J ClinMicrobiol Infect Dis. 2014 Jan; 33(1): 135-41. doi: 10.1007/s10096-013-1939-0. PubMed PMID: 23907587.

3. Nace HL, Horn D, Neofytos D. Epdidemiology and outcome of multiple-species candidemia at a tertiary care center between 2004 and 2007. Diagn Microbio Infect Dis. July 2009; 64(3): 289-294. doi: 10.1016/j.diagmicrobio.2009.03.010. PubMed PMID: 1376670.

4. Larru B, Barret DM, Gerber JS. Candida krusei arthritis in an adolescent with acute myelogenous leukemia. Pediatr Infect Dis J. 2013 Oct; 32(10): 1142-4. doi: 10.1097/INF.0b013e318294b012. PubMed PMID: 23563520.
5. Slenker AK, Keith SW, Horn DL. Two hundred and eleven cases of Candida osteomyelitis: 17 case reports and a review of the literature. Diagn Microbiol Infect Dis. 2012 May;73(1): 89-93. doi: 10.1016/j.diagmicrobio.2012.02.004. PubMed PMID: 22578942

6. Gamaletsou MN, Kontoyiannis DP, Sipsas NV, Moriyama B. Candida osteomyelitis: analysis of 207 pediatric and adult cases(1970-2011). Clin Infect Dis. 2012 Nov 15; 55(10):1338-51. doi: 10.1093/cid/cis660. PubMed PMID: 22911646.

7. Wang HP, Yen YF, Chen WS, Chou YL, Tsai CY, Chang HN. An unusual case of Candida tropicalis and Candida krusei arthritis in a patient with acute myelogenous leukemia before chemotherapy. Clin Rheumatol. 2007 Jul; 26(7): 1195-1197. PubMed PMID: 16767352.

8. Grunspun H, Pitta FP, Santos DC, Serpa BS. Sternoclavicular joint septic arthritis in a previously healthy adult. Einstein. 2008 6(4)487-90 